\title{
Correspondence
}

\section{Why We Should Discount the Views of Those Who Discount Discounting}

Lisa Heinzerling, Regulatory Costs of Mythic Proportions, 107 YALE L.J. 1981 (1998).

\section{John J. Donohue III}

Deciding how to allocate the resources to be spent on promoting health and safety through governmental regulation is a challenging task of immense significance. The Environmental Protection Agency estimates that roughly $\$ 250$ billion (2.6\% of Gross National Product) will be spent on pollution abatement alone in the year 2000. ${ }^{1}$ Billions more are spent on a wide array of other health and safety measures. Tens of thousands of lives will be lost or saved depending on whether these allocations are made foolishly or wisely. ${ }^{2}$

In 1986, Office of Management and Budget (OMB) economist John Morrall devised a now-famous table designed to assess the desirability of an array of federal health and safety regulations. ${ }^{3}$ Morrall concluded that roughly half of the forty-four regulations he reviewed were unsound because the cost per life saved exceeded $\$ 26.8$ million in 1998 dollars ${ }^{4}-a$

$\dagger$ Professor of Law and John A. Wilson Distinguished Faculty Scholar, Stanford Law School. My thanks to Bernard Black, Richard Craswell, Jim Salzman, and Peter Siegelman for thoughtful comments on an earlier draft of this work.

1. See Adam B. Jaffe et al., Environmental Regulation and the Competitiveness of U.S. Manufacturing: What Does the Evidence Tell Us?, 33 J. ECON. LITERATURE 132, 140 (1995). Since 1970, these regulations have reduced carbon monoxide and particulate emissions by over $50 \%$ and lead emissions by $98 \%$. See id. at 134 tbl.1. A question exists as to whether better regulations could have given us the same, or even greater, benefits at only a fraction of the cost. tbl.4.

2. See John F. Morrall III, A Review of the Record, REgulation, Nov.-Dec. 1986, at 30

3. See id. at 25 .

4. Figure derived from converting $\$ 17.1$ million cost per life saved for benzene regulations to 
figure substantially higher than the amount of money that workers would demand in exchange for a comparable increased risk of death on the job. ${ }^{5}$

In her provocative article, Regulatory Costs of Mythic Proportions, ${ }^{6}$ Lisa Heinzerling illustrates how "the table" has taken on a life of its own as it has become "Exhibit $\mathrm{A}^{\text {" }}$ in the case against the soundness of current regulatory decisionmaking. She documents how the table has been widely cited for the propositions that "the costs of regulation often exceed its benefits, that many more cost-effective strategies exist for reducing risk, that regulation sometimes increases overall risk, and that regulatory priorities are not set in a rational manner." 8

Heinzerling has selected a marvelous topic and has exhaustively probed beneath the surface of a widely accepted study to see if its conclusions can withstand close scrutiny. She has taken Morrall's very lean report and admirably fleshed out the details behind many of the forty-four regulations that each appear as just one line in Morrall's table. Heinzerling legitimately questions whether Morrall's selection of regulations is representative or overweighted toward less cost-effective rules. ${ }^{9}$ She demonstrates that Morrall's cost and benefit estimates are not always well-documented and are consistently less optimistic than the estimates of the agencies issuing the rules, ${ }^{10}$ and she observes that a number of the worst-performing regulations on Morrall's list were withdrawn or never adopted because their costs far exceeded their benefits. ${ }^{11}$ By accounting for these factors, Heinzerling suggests that only eleven of the forty-four regulations reviewed by Morrall are cost-ineffective, rather than twenty-two, as Morrall claimed. ${ }^{12}$

Ascertaining that only $25 \%$ of federal regulations were defective would be an interesting conclusion-although perhaps not the ringing endorsement of regulatory policy that Heinzerling seeks. Heinzerling attempts, however, to further whittle the number of cost-ineffective regulations from eleven to two. She argues that Morrall improperly uses a

1998 dollars. See id. at 30 tbl.4.

5. See id. at 34 .

6. Lisa Heinzerling, Regulatory Costs of Mythic Proportions, 107 YALE L.J. 1981 (1998).

7. Id. at 1994.

8. Id. at 1983.

9. See id. at 2000-17.

10. See id. at 2017-42.

11. See id. at 2000-10. Heinzerling notes the irony of including examples of unwise rules that were rejected in a table that is held up as an indication of severe regulatory failure. Her criticism of Morrall on this point seems a bit uncharitable, however, since his table explicitly identifies whether regulations were implemented, rejected, or merely proposed. Moreover, the process that led to the withdrawal of these regulations included procedures that Heinzerling would eliminateOMB review and consequent sharp criticism of rules that severely failed a cost-benefit test.

12. See id. at 1998-2014. Indeed, by relying on agency estimates that are uniformly more favorable than Morrall's, Heinzerling concludes that even fewer than eleven of these regulations are cost-ineffective. See id. at 1985. My guess is that if she had examined the agency estimates with the same critical eye that she used for examining Morrall's figures, Heinzerling could have raised many questions about their accuracy and consistency as well. 
$10 \%$ discount rate to determine the cost per life saved of government regulation, and she instead proposes a discount rate of zero. She even suggests that cost-benefit analysis should be jettisoned altogether. These arguments go too far. Had Heinzerling been content to make the case that $10 \%$ is too high a discount rate and that some lower but still positive discount rate should be used, her work would have made a major contribution to the literature. But by arguing that the quantification involved in cost-benefit analysis is harmful and that discounting future benefits is wrong, Heinzerling has impaired the value of her paper.

This Correspondence makes the following points: (1) cost-benefit analysis is a useful tool for improving the quality of regulatory decisionmaking; (2) whether one evaluates regulations using either the cost per life saved approach-so-called cost-effectiveness analysis-or instead uses standard cost-benefit analysis, one should discount future benefits using a reasonable discount rate or a range of rates; and (3) if Morrall is guilty of exaggerating the unattractiveness of many regulations, then Heinzerling is equally guilty of exaggerating their desirability by failing to discount future benefits. Following Heinzerling's advice to avoid discounting and cost-benefit analysis generally would likely undermine rational decisionmaking, thereby increasing the number of misguided regulations and increasing overall risk.

\section{THe VAlue OF Cost-Benefit ANALYsis}

Heinzerling suggests that numbers will be too persuasive and that we should therefore jettison the whole enterprise of cost-benefit analysis. ${ }^{13}$ This seems a hasty judgment of a tool designed to promote wise decisionmaking. Requiring agencies to set forth the relevant costs and benefits carefully helps them to rationalize their regulatory agenda and enables independent analysts to evaluate the soundness of particular regulations. Just as the practice of requiring judges to explain their decisions improves the quality of judicial decisionmaking, the requirement that agencies systematically consider and document the effects of their decisions will improve the quality of agency decisionmaking. Light is the best germicide-and all that. This is why a distinguished panel of economists has set forth guidelines calling on agencies to "spell out all key assumptions clearly and highlight uncertainties" in conducting cost-benefit analyses of major regulations. ${ }^{14}$ This should be the message that academics convey to our regulators, politicians, judges, and citizens.

13. See id. at 2042, 2064-69.

14. KenNeth J. ARrow et al., BeneftT-Cost ANAlysis in EnVIRonMENTAl, Health, AND SAFETY REGULATION: A STATEMENT OF PRINCIPLES 12 (1996). 
While cost-benefit analysis can aid the regulatory process, however, its limitations must be acknowledged. Judgment must still be exercised across a vast array of issues, such as distributional concerns, possible irreversible consequences, and the treatment of considerations not easily susceptible to quantification. Moreover, the process is impaired when advocates for or against regulation present biased estimates, as they typically do. ${ }^{15}$ Two steps that should improve the quality of federal regulations are the 1997 congressional directive that the OMB begin reviewing all new federal regulations, and the creation of the new Joint Center for Regulatory Studies. The Center, jointly sponsored by the conservative American Enterprise Institute and the liberal Brookings Institution, provides independent costbenefit analyses of big-ticket federal regulations each year. ${ }^{16}$ This promises exactly the type of peer review that has so often been lacking.

While Heinzerling points to immensely wide-ranging estimates of the costs and benefits of particular regulations as evidence against Morrall's view of a chaotic regulatory process, ${ }^{17}$ the estimates convey to me the need for as much order, consistency, and quantification as possible. The idea that better decisions could be obtained by keeping the picture more "blurry," as Heinzerling suggests, ${ }^{18}$ is baffling. The adoption of Heinzerling's approach would needlessly sacrifice lives.

\section{THE NEED To DISCOUNT FUTURE BENEFITS}

To evaluate a proposed regulation, one would ideally like to ascertain all of the relevant costs and benefits and identify when each would be incurred. Since " $[b]$ oth economic efficiency and intergenerational equity require that benefits and costs experienced in future years be given less weight in decisionmaking than those experienced today," ${ }^{19}$ the process of discounting the future costs and benefits to current dollars has become standard. ${ }^{20}$ Expressing all costs and benefits in current dollars should yield valuable information about the wisdom of adopting a particular proposal.

Discounting the monetary value of future lives embodies the

15. As Robert Litan, an economist at the Brookings Institution and co-director of the Joint Center for Regulatory Studies, puts it: "The only comments regulators generally get are selfinterested comments." Peter Passell, A New Project Will Measure the Cost and Effect of Regulation, N.Y. TIMES, July 30, 1998, at D2 (quoting Robert Litan).

16. See id.

17. See Heinzerling, supra note 6, at 2041 n.404. For example, she notes that the estimates of cost per life-year saved by regulating low-arsenic copper smelters range from $\$ 2.6$ million to $\$ 890$ million.

18. Id. at 2069.

19. ARROW ET AL., supra note 14 , at 13.

20. OfFice of INFo. \& Regulatory AfFairs, Office of MANAGEMENT \& Budget, ECONOMIC ANALYSIS OF FEDERAL REGULATIONS UNDER EXECUTIVE ORDER 12866, at 9-11 (1996) [hereinafter 1996 OMB ANALYSIS]. 
assumption that if you had a choice between spending $\$ 40$ million to save either ten lives today or ten lives in a little over seven years, you would choose to save the ten lives today. Concern for lives in the future would be better addressed by investing the $\$ 40$ million today, which, at a $10 \%$ interest rate, would grow to $\$ 80$ million in approximately seven years. This larger sum could then be used to save more than ten lives. While human lives are priceless from a philosophical or religious perspective, the resources that can be used to save lives are limited. If we fail to recognize this economic reality as we go about the process of choosing regulations, we will expend resources in a way that prevents us from saving as many lives as possible. It is not the idea that future lives are less valuable in any moral or ethical sense that leads to the process of discounting at a current rate of interest. Rather, discounting is appropriate in that, if invested, our resources are expected to grow at that rate, so that if we forego spending and invest the money instead, we can save more lives in the future with the amount foregone today. ${ }^{21}$

In addressing the propriety of discounting, Heinzerling draws an untenable distinction between the appropriate use of discounting in traditional cost-benefit studies and Morrall's use of a discount rate in implementing his cost-per-life-saved approach. ${ }^{22}$ Heinzerling argues that since Morrall did not express a monetary value of life, he should not discount the future lives saved by the regulations he evaluates. ${ }^{23}$

But if it is appropriate to discount in the traditional cost-benefit analysis, then it is also appropriate for Morrall to have done so in his costper-life-saved approach. The two are mathematically equivalent. ${ }^{24}$ Heinzerling improperly draws rhetorical support for her position-that we should not "discount" lives saved in the future-by invoking the layman's

21. Of course, as Heinzerling notes in her reply, one needs to discount the future benefits to generate a determinate outcome, otherwise any expenditure that would generate a savings of one life each year in perpetuity would necessarily be deemed to have an infinite benefit juxtaposed against the finite cost.

22. See Heinzerling, supra note 6, at 2043 ("As long as the value of human life is measured in dollars, the justification for discounting remains .... If lives are commensurate with dollarsthe premise of the monetary valuation of a human life-then there appears to be little reason to object, in principle, to the idea of discounting the monetary equivalent of a human life, just as there is little reason to object to the idea of discounting any future sum of money to present value.").

23. See id. at 2044-46. Heinzerling also argues that it may be appropriate to discount future costs but not future benefits, see id. at 2052-53, but this claim is irrational. It would argue that we should spend lots of money to save lives in the distant future even though we would not spend that same amount to save a similar number of lives right now.

24 . To see this, consider a regulation that would impose a $\$ 4$ million cost today while saving one future life, which is valued at $\$ 5$ million at the time it is saved. Without discounting, the regulation looks appealing, but if the present value of the life saved is only $\$ 2.5$ million with discounting, the regulation would fail the cost-benefit test. A cost-per-life-saved approach would generate the same negative conclusion if we discounted the one life saved to one-half of a life, but would lead to a more positive assessment if we failed to discount and deemed the cost per life saved to be only $\$ 4$ million. 
notion of discounting as somehow devaluing future lives, rather than the analyst's conception of it as a tool to convert all costs and benefits into a single present value calculation. Yet it is only the happenstance that Morrall employed a cost-per-life-saved calculation that enables Heinzerling to marshal this rhetorical opposition. ${ }^{25}$ In this sense, the rhetoric about "discounting lives" is a mere distraction, since traditional cost-benefit analysis would simply be discounting dollars.

\section{ChOOSING THE APPROPRIATE SOCIAL Discount RATE}

Heinzerling would have done a great service if she had simply argued for a lower discount rate and shown how the use of a high discount rate (like Morrall's) systematically discourages regulations that will control diseases with long latency periods. While a zero discount rate is clearly too low, a $10 \%$ real discount rate may be almost as evidently too high. ${ }^{26}$

As it turns out, there is no single correct answer to the choice of the appropriate discount rate for public projects. The return on marginal resources invested in the corporate sector is artificially elevated because of the presence of corporate income taxes and a private risk premium that attaches even though there is no risk from the perspective of society as a whole. At the same time, the public's time discount rate is substantially lower-perhaps proxied by the riskless government bond interest rate. Efficiency in allocating resources between the public and private sectors would argue for the higher discount rate reflective of returns in the private sector, while efficiency in intertemporal allocation would argue for a lower rate lest we allocate too few resources to the future. ${ }^{27}$ After discussing these issues, William Baumol concludes that the use of a low discount rate by the government would lead to investments with meager long-term returns compared to those available for investments in private businesses. ${ }^{28}$

25. Morrall used this approach to avoid the task of specifying the monetary value of a saved life, which is a controversial step of all cost-benefit analyses. See Morrall, supra note 2, at 31 .

26. Before denouncing Morrall for his choice, one must remember that he was an OMB employee at the time that he wrote his 1986 article and that the then-current OMB guidelines called for the use of a 10\% discount rate for all cost-benefit studies. See OFFICE OF MANAGEMENT \& Budget, EXECUtive OfFICE OF THE PRESIDENT, CirCUlaR A-94 REVISED 4 (1972). OMB has now lowered its recommended discount rate to $7 \%$. See OfFICE OF MANAGEMENT \& Budget, EXeCUtive OfFice of tHe PRESIDENT, CirCular A-94 Revised 8.b.1 (1992). Nonetheless, it is certainly legitimate to question whether even this rate is too high, as others have done. See, e.g., Daniel Farber \& Paul Hemmersbaugh, The Shadow of the Future: Discount Rates, Later Generations, and the Environment, 46 VAND. L. REV. 267, 270 (1993).

27. Imagine a choice between a public investment that would generate a $2 \%$ return and a private investment of the same magnitude that would yield an $8 \%$ return. It is conceivable that the tax revenue generated by the private investment would outweigh the return from the public investment. While the private investment would clearly seem to dominate the public investment in this case, the adoption of a very low social rate of discount might channel resources from such private use to the less valuable public use.

28. See William J. Baumol, On the Social Rate of Discount, 58 AM. ECON. REv. 788, 801 
Heinzerling gives little weight to Baumol's concern.

Heinzerling does quote and endorse Baumol's suggestion that a lower or perhaps zero discount rate may be appropriate in certain circumstances, such as when the goal is to prevent irreversible environmental damage. ${ }^{29}$ But Baumol's suggested special treatment to avoid irreversible disastrous consequences was to subsidize selectively the investments needed to address them. He specifically rejected Heinzerling's resort to "a low general discount rate that encourages indiscriminately all sorts of investment programs whether or not they are relevant." 30

One may think of regulatory policy as requiring two fundamental decisions: (1) the determination of the amount of resources that society will spend to save (and enhance) lives; and (2) the determination of how those resources should be spent on particular life-saving regulations or expenditures. My guess is that Heinzerling hopes that her criticism of discounting might lead society to spend more money on lifesaving measures. Heinzerling argues that since it is worse to have underestimated a risk than to have overestimated it, we should be sure to use high-end estimates of the benefits of regulation. ${ }^{31}$

But while it is nice to be on the side of the angels, we cannot overlook the fact that overregulation has costs too. Individuals spend their own money on reducing risks, and if regulation drives up costs sufficiently to reduce personal income, then some of these personal health and safety investments will be displaced. If we overinvest in regulations that have dubious value, we may save some lives through the direct regulation, but lose even more from the foregone future investments in health that we have crowded out. ${ }^{32}$ Moreover, by failing to use a discount rate, we will encourage spending on projects that have distant payoffs. If the goal is to save more lives, one should instead ratchet up the monetary estimate of how much society is willing to spend to save a life. If inadequate measures are being taken to save lives when, say, $\$ 5$ million is the estimated value, one can raise the monetary estimate to some higher figure..$^{33}$

(1968) ("It is my inclination at the moment to look with some favor at a figure toward the higher end of the range-at a discount rate closer to what may be considered the cost of capital to private firms. My grounds for this preference are hardly convincing even to me-they rest largely on the feeling that there is a very tangible loss in the transfer of resources from a high rate of return use to an employment in which their yield is very low.").

29. See Heinzerling, supra note 6, at 2052 (quoting Baumol, supra note 28, at 801).

30. See Baumol, supra note 28 , at 801 .

31. See Heinzerling, supra note 6, at 2044-45.

32. Recall that spending $\$ 5$ million today to save a life in the distant future requires foregoing (1) the option of saving a life today for $\$ 5$ million and (2) the option of investing that $\$ 5$ million, which will grow to a much higher sum that can save many more lives in the future. This is the sense in which dollars and lives become commensurable, since if you have the dollars you can save lives.

33. Similarly, Heinzerling questions the argument that the greater wealth of future generations implies that we should discount future benefits. She replies that the richer generations 
In the end, there is no single appropriate discount rate. Uncertainty is inherent in the choice of a discount rate, and a range of rates should be employed. ${ }^{34}$ Of course, the use of differing discount rates implies that judgment will have to be exercised when the resulting cost-benefit calculations lead to conflicting conclusions.

\section{CONCLUSION}

As the latest OMB guidelines on cost-benefit analysis emphasize, there is no "mechanistic blueprint" for policy evaluation. ${ }^{35}$ Rather, "[c]ompetent professional judgment is indispensable for the preparation of a high-quality analysis." ${ }^{36}$ Rigorous probing of cost and benefit estimates (of the sort that Heinzerling directs at Morrall's table) can help refine and improve regulatory studies. Heinzerling's recommendations to jettison the valuable tools of discounting and cost-benefit analysis, however, would leave policy to be influenced more by rhetoric rather than by reason. This is an ancient debate that was at the heart of Plato's dialogue, Gorgias, in which Socrates argued for expertise to guide policy while his opponents, Gorgias and Callicles, sought to rely on rhetoric. ${ }^{37}$ Here, I side with Plato and Socrates.

While Heinzerling's anti-discounting rhetoric may be moving, it has the untoward consequence of making it seem that those who would be saving lives by appropriate regulatory decisionmaking are harsh and callous because they "discount lives." Yet no one suggests that lives should be discounted in the popular meaning of that term-devalued or disregarded. Proper discounting can aid in the important process of channeling resources to their highest-valued uses, which can promote greater health and wellbeing for both present and future generations. The fact that some policymakers, such as $\mathrm{Al}$ Gore, have denounced the practice of discounting raises concerns over whether these judgments will be made wisely. ${ }^{38}$

$* * *$

The Western capitalist countries have benefited greatly by their ability to invest private capital in efficient ways-that is, by investing in projects whose cost is exceeded by the present value of future income streams. The

will therefore value life more. See Heinzerling, supra note 6, at 2044-45. But it seems illogical to argue that because future generations will have more money than we do at present, we (who are poorer) should spend more to save one life in the future than to save one present life.

34. See ARROW ET AL., supra note 14, at 13.

35. 1996 OMB ANALYSIS, supra note 20, at 3.

36. $I d$.

37. See Plato, Gorgias 28-32 (Walter Hamilton trans., Penguin Books 1960).

38. See AlBERT GORE, EARTH IN THE BALANCE: ECOLOGY AND THE HUMAN SPIRIT 190-91 (1992). 
resulting increased wealth has greatly enhanced the health and longevity of the citizens of these countries. When government considers spending resources on health-improving measures it must be mindful that its expenditures may curtail private wealth-creating investments and personal expenditures on health-promotion and lifesaving. If high-return private investments are crowded out by low-return governmental expenditures, the government may be lowering social wealth, health, and well-being. Since discount rates are an important policing mechanism for determining profitable investments, they must be a concern of governmental decisionmakers who care about the aggregate well-being of the populace.

In general, the governmental interest in determining what people are willing to pay to extend their lives is premised on the belief that if a citizen is to pay (through taxation) for a governmentally provided life-extending measure, then it is helpful to know whether he would willingly spend the money himself to achieve a similar health benefit. If he would prefer having the money to getting the benefit, it may be unwise to tax him to give him a benefit that he values less than the tax revenue. This explains why more can be taken from and therefore spent on benefiting the rich-since they are happy to spend more on extending their lives. A far less affluent person would likely pray that the government. would not tax him to spend the same amount that the rich man would pay for life extension, since the poorer individual would generally prefer the money. The less affluent person would certainly not want to be taxed highly to make the rich healthier. This discussion may suggest the error in Heinzerling's suggestion that because future generations will be richer, we must spend more on saving their lives. No. We, who are poorer, will not value the lives of the future rich more highly simply because they will be rich. Just as today's poor will not spend enormous amounts to promote the health of today's rich (or entreat the government to tax them to do so), the relatively poor of today (vis-à-vis the citizens of the future) will not want the government to tax them to provide extraordinary lifesaving benefits for richer future generations.

Heinzerling makes the point that financial rates of return, and hence discount rates, have nothing to do with judgments about the relative worth of present and future people (p.1914) ${ }^{39} \mathrm{I}$ am happy to accept this statement as long as "worth" is thought of in a spiritual, ethical, or religious sense. This discussion may suggest the basis for my disagreement with the view that future benefits-and especially future lives-are without moral or ethical value simply because their discounted present value approaches zero. For example, I do not spend a lot of time worrying about the welfare of my neighbor's children even though I am constantly concerned about the

39. Parenthetical page references are to Lisa Heinzerling, Discounting Life, 108 YALE L.J. 1911 (1999). 
welfare of my own children. In the narrow sense that Heinzerling employs, one might say that I "devalue the life of these other children relative to my own" since I spend nothing to improve their welfare. But I reject the idea that my children are in any ultimate moral or ethical sense more valuable than my neighbor's children. I do not have to spend time worrying about my neighbor's children because my neighbor can take care of them just fine, and I apply the same thinking, absent exceptional circumstances, to distant future generations. I am not willing to spend a lot of money to help very remote future generations, because I think they will be just fine without my concern and resources-indeed, there is every reason to think that their lives will be far more pleasant than those of the current generation. Discounting gives a rational method for trading off the expenditures across generations, but as I noted in my discussion of the appropriate discount rate, in special circumstances where the interests of the future generation are such that my stated assumption is inaccurate, then one might depart from the general approach and choose to favor future generations by using a low or even zero discount rate, or subsidizing an important investment. This type of special treatment might be appropriate in the case of some irreversible environmental damage, much as my attitude towards the welfare of my neighbor's children would be changed if my neighbor could not for some reason take care of them.

I disagree with Heinzerling's views on (1) the significance of the increasing cost of lifesaving technologies (p. 1911), which I believe confuse the difference between real and nominal; (2) the indivisibility of lives (p.1913), which are in fact temporally quite divisible since no life is ever saved-only days or years of life are saved; (3) the conception that the timing of the benefit of a reduction in risk is immediate even if the savings of life-years occurs far in the future (p. 1913), which can irrationally favor less effective lifesaving technologies; and (4) her notion that the central issues of discount rate determination are "dated" (even though her proffered list of supposedly up-to-date considerations includes merely reformulations or refinements of the central issues) or even irrelevant to the issues of government regulation (p. 1914).

Of course, anomalies will necessarily be present in any exercise of public decisionmaking, but I would submit that a rigorously documented cost-benefit analysis can illuminate the issues of relevance in assessing the impact on aggregate welfare of a particular project or regulation. This means neither that one must be a slave to such an analysis nor that distributive or deontological considerations never trump the analysis, but that, as a pragmatic matter, the general use of cost-benefit analysis, though certainly no panacea, probably promotes the general welfare by systematically leading to better decisions than would be achieved through ad hoc evaluations. 